Japan. J. Med. Sci. Biol., 22, 43-50, 1969

\title{
TYPHOID H-AGGLUTININS IN CLONORCHIS INFESTATED GUINEA PIGS
}

\author{
C. T. HUANG AND C. H. CHAN-TEOH \\ Department of Microbiology, University of Hong Kong, Hong Kong
}

(Received: December 27th, 1968)

\begin{abstract}
SUMMARY: When typhoid vaccine was injected to Clonorchis sinensis infestated guinea pigs, the titer of the H-agglutinins in response to the injection was reduced in the infestated animals as compared with the uninfestated controls. Moreover, the heavier the infestation the lower was the agglutinin response. It was suggested that compression of the liver cells by the fibrosis around intrahepatic bile ducts as a result of the infestation contributed to the variation in antibody response in the infestated animals.
\end{abstract}

\section{INTRODUCTION}

The role of the normal liver in antibody production is poorly defined. According to Humphrey and White (1963), antibody production within the liver could usually correlate with the presence of invading cells forming scattered periportal granulomata and the true hepatic parenchymal cells do not make antibody. Eichman, Miller and Havens (1953) found that there was no significant difference in antitoxin production between patients with acute viral hepatitis and the essentially normal controls following intramuscular injection of purified diphtheria toxoid. McFadzean and Tsang (1956) reported, however, that the mean maximum hemolytic titers after intravenous injection of washed sheep-erythrocytes into cryptogenic splenomegaly patients were significantly lower in those with cirrhosis of the liver than those without cirrhosis or the normal controls.

Hou (1955) observed that the most marked pathology in clonorchiasis in man was adenomatosis with connective tissues proliferation of the wall of the bile ducts, but in experimental infestated animals multiple scars were constantly seen between the dilated bile ducts with disappearance of the liver cells and that multilobular cirrhosis was not established. Because of the extensive scar lesions in the liver of infestated small laboratory animals, guinea-pigs were fed with metacercariae of Clonorchis sinensis and then immunized with formalinized typhoid vaccine, so that the rise and fall of the agglutinin titers in the blood of the infestated animals can be compared with that of the uninfestated. The purpose is to clarify whether compression of the liver cells due to clonorchiasis would have any effect on the overall antibody production capacity of the infestated host. This paper is to report the results of such an investigation.

Materials AND MethodS

Infestation of guinea pigs with Clonorchis sinensis: Guinea pigs weighing 300- 
$400 \mathrm{~g}$ were fed with flesh of cypriniidae fish containing metacercariae of $C$. sinensis. The guinea pigs were starved the evening before the feeding and in the morning about $10 \mathrm{~g}$ of fish meat were given per head. Since guinea pigs did not tolerate fish meat well, the feed was given in alternative days and continued for 6 weeks. Thus a total of 20 feeds were blindly given irrespective of the number of cysts containing in the flesh of the fish. In between feeds, ordinary diet was supplied. Four weeks after the last feed, ova count of $C$. sinensis for each animal was performed.

The total amount of $24 \mathrm{hr}$ faecal matters was collected from the pan of the cage of each animal and ground in a motar to mix. The mixed stool was used for ova count by the Stoll-Hauseer technique (Faust and Russell; 1964). The result of each count was calculated from the average of the numbers of ova of three smears and the count was expressed in terms of numbers of ova per gram of faeces per diem.

Immunization of guinea pigs with typhoid vaccine: The infestated animals were divided into two groups according to their ova counts. They were arbitrarily chosen so that group A consisted of those which have an ova count of 200 and group B have an ova count ranging from 1,000 to 2,700 per gram per diem. Thus, these two groups represented those with light and heavy infestations, respectively. A third group of uninfestated guinea pigs (group C) having approximately the same body weights as the infestated when immunization began was also injected as control.

Formalin treated cultural suspension of Salmonella typhi containing approximately 100 million organisms per $\mathrm{ml}$ was the antigen suspension for injection into guinea pigs. Before immunization, the guinea pigs were bled and pooled sera from each group were tested for absence of non-specific agglutinins against $S$. typhi.

The course of immunization was carried out with subcutaneous injections of $0.25 \mathrm{ml}$ of the antigen suspension given twice weekly for four weeks. The animals were allowed to rest for 2 weeks. At the end of the 16 th week after the first injection, a single booster dose of $0.5 \mathrm{ml}$ of the antigen suspension was injected through the same route. During the course, guinea pigs were bled and tested for flagellar $(\mathrm{H})$ agglutinin at weekly intervals until the end of the 8th week and again from 17 th to the 23rd week. The agglutination test followed the standard procedures with two-fold dilutions of the sera ranging from 1 in 20 to 1 in 5120 and the antigen-antibody mixtures were incubated at $45 \mathrm{C}$ for $2 \mathrm{hr}$ before readings were made.

\section{RESULTS}

\section{Clonorchis Infestation in Guinea Pigs}

With an ova count of 200 , the number of worms recovered from the bile ducts of a guinea pig varied from 2 to 4 and those with an ova count of 1,000 , there will be approximately $10-15$ worms. The ratio of worm count to ova count in our cases was close to the estimation of Faust and Khaw (1927), who found that a clonorchis worm produced approximately 85 ova per gram of faeces per diem.

Macroscopically, there was cystic dilatation of the intrahepatic ducts, which 
has become prominent after 2 months of infestation and usually the ventral lobe of the liver was involved (Fig. 1).

Microscopically, the portal areas were widened and showed marked proliferation of bile duct epithelium in the form of solid cords or small tubules. The intervening stroma was very scanty and infiltrated by moderate numbers of eosinophils, mononuclear cells and a few plasma cells. Part of the worms were seen in the lumen of the larger bile ducts. Here the lining was also markedly hyperplastic. The infoldings into the lumen were covered by a layer of closely arranged tall columnar cells. The hyperplastic epithelium beneath the luminal surface assumed an adenomatous pattern. The periductal fibrosis stroma was increased and infiltrated by many eosinophils, mononuclear cells and few plasma cells. Liver cells adjoining the widened portal areas were compressed, but no noteworthy features were present.

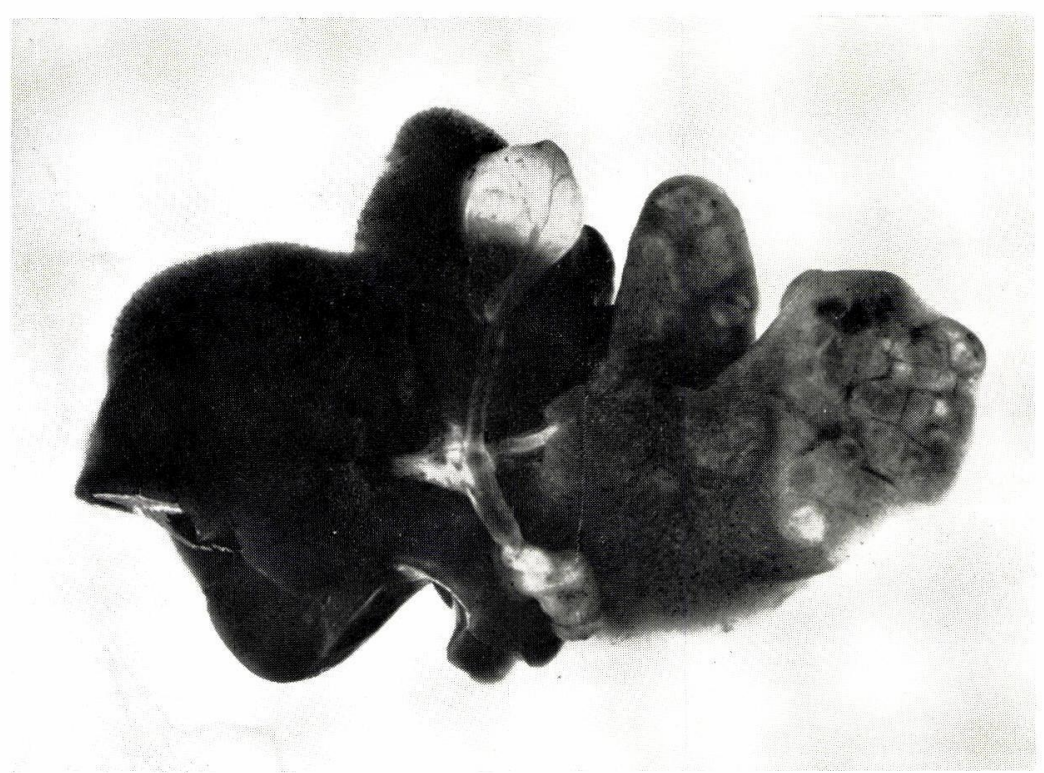

Fig. 1. Macroscopic appearance of guinea pig liver heavily infestated with Clonorchis sinensis.

\section{Agglutinin Titers of Guinea Pigs after Immunization}

The distribution of the H-agglutinin titers during the course of investigation in the three groups of guinea pigs are presented in Tables 1, 2 and 3. To enable easy calculation of the means, the agglutinin titers are presented in terms of scores. A score of 1 was given to a positive titer of 1 in 20 dilution of the serum and 2 for 1 in 40, and so on until a score of 9 was given to a dilution of 1 in 5120 , the last of the series. The rise and fall of the mean agglutinin titers of the three groups is graphically presented in Fig. 2. Table 4 shows the $t$ values between the means of each of the infestated groups and the control, and between the two infestated groups.

As is shown in Fig. 2, the patterns of rise and fall of mean agglutinin titers 
Table 1. Agglutinin-titer scores of guinea pigs with light infestation (Group A)

\begin{tabular}{|c|c|c|c|c|c|c|c|c|c|c|c|c|c|c|c|c|c|}
\hline \multirow{2}{*}{$\begin{array}{l}\text { G. P. } \\
\text { No. }\end{array}$} & \multirow{2}{*}{$\begin{array}{c}\text { Ova } \\
\text { count }\end{array}$} & \multicolumn{16}{|c|}{ Week after first injection of antigen } \\
\hline & & 1 & 2 & 3 & 4 & 5 & 6 & 7 & 8 & & 17 & 18 & 19 & 20 & 21 & 22 & 23 \\
\hline 1 & 200 & 0 & 2 & 3 & 2 & 2 & 1 & 1 & 1 & \multirow{12}{*}{ 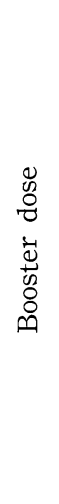 } & 4 & 4 & 2 & 8 & 6 & 5 & 5 \\
\hline 2 & "l & 0 & 2 & 3 & 1 & 3 & 2 & 0 & 0 & & 5 & 6 & 1 & 6 & 4 & 4 & 3 \\
\hline 3 & "I & 0 & 2 & 3 & 2 & 3 & 3 & 0 & 0 & & 4 & 5 & 0 & 8 & 5 & 4 & 4 \\
\hline 4 & "I & 0 & 4 & 2 & 3 & 2 & 2 & 0 & 0 & & 4 & 5 & 0 & 6 & 5 & 5 & 4 \\
\hline 5 & "I & 0 & 2 & 3 & 4 & 4 & 3 & 1 & 1 & & 4 & 4 & 3 & 8 & 7 & 6 & 6 \\
\hline 6 & " & 0 & 1 & 3 & 3 & 2 & 2 & 1 & 0 & & 2 & 3 & 0 & 4 & 3 & 2 & 2 \\
\hline 7 & "I & 0 & 3 & 6 & 4 & 4 & 3 & 3 & 1 & & 2 & 5 & 1 & 5 & 4 & 3 & 3 \\
\hline 8 & "I & 0 & 5 & 3 & 5 & 6 & 2 & 1 & 0 & & 0 & 4 & 0 & 4 & 5 & 6 & 4 \\
\hline 9 & "I & 0 & 4 & 4 & 4 & 3 & 2 & 1 & 0 & & 0 & 5 & 0 & 4 & 3 & 3 & 3 \\
\hline 10 & "I & 0 & 0 & 1 & 2 & 3 & 3 & 0 & 1 & & 0 & 5 & 0 & 4 & 5 & 3 & 3 \\
\hline 11 & "I & 0 & 0 & 4 & 4 & 3 & 0 & 0 & 0 & & 0 & 4 & 0 & 3 & 5 & 4 & 3 \\
\hline 12 & "l & 0 & 0 & 4 & 5 & 3 & 2 & 0 & 0 & & 0 & 4 & 1 & 4 & 5 & 3 & 3 \\
\hline \multicolumn{2}{|c|}{ Total } & 0 & 25 & 39 & 39 & 38 & 25 & 8 & 4 & & 25 & 54 & 8 & 64 & 57 & 48 & 43 \\
\hline \multicolumn{2}{|c|}{ Mean } & 0 & 2.0 & 3.2 & 3.2 & 3.1 & 2.0 & 0.6 & 0.3 & & 2.0 & 4.5 & 0.6 & 5.3 & 4.7 & 4.0 & 3.5 \\
\hline
\end{tabular}

Table 2. Agglutinin-titer scores of guinea pigs with heavy infestation (Group B)

\begin{tabular}{|c|c|c|c|c|c|c|c|c|c|c|c|c|c|c|c|c|c|}
\hline \multirow{2}{*}{$\begin{array}{c}\text { G. } P . \\
\text { No. }\end{array}$} & \multirow{2}{*}{$\begin{array}{c}\text { Ova } \\
\text { count }\end{array}$} & \multicolumn{16}{|c|}{ Week after first injection of antigen } \\
\hline & & 1 & 2 & 3 & 4 & 5 & 6 & 7 & 8 & & 17 & 18 & 19 & 20 & 21 & 22 & 23 \\
\hline 21 & 1000 & 0 & 1 & 3 & 3 & 4 & 4 & 1 & 1 & \multirow{8}{*}{ 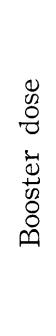 } & 0 & 5 & 3 & 5 & 5 & 5 & 4 \\
\hline 22 & 1000 & 0 & 0 & 2 & 3 & 4 & 4 & 3 & 1 & & 0 & 4 & 3 & 4 & 3 & 3 & 3 \\
\hline 23 & 1000 & 0 & 0 & 1 & 3 & 0 & 3 & 0 & 0 & & 7 & 5 & 3 & 7 & 6 & 7 & 3 \\
\hline 24 & 1200 & 0 & 0 & 1 & 0 & 1 & 0 & 0 & 0 & & 1 & 2 & 1 & 5 & 3 & 3 & 3 \\
\hline 25 & 1400 & 0 & 2 & 2 & 1 & 0 & 2 & 0 & 0 & & 3 & 2 & 1 & 5 & 5 & 5 & 3 \\
\hline 26 & 1400 & 0 & 0 & 1 & 3 & 3 & 1 & 0 & 0 & & 1 & 2 & 3 & 4 & 3 & 3 & 2 \\
\hline 27 & 2000 & 0 & 0 & 0 & 3 & 2 & 1 & 0 & 0 & & 4 & 5 & 2 & 5 & 3 & 4 & 2 \\
\hline 28 & 2700 & 0 & 6 & 3 & 4 & 5 & 4 & 2 & 01 & & 5 & 4 & 4 & 5 & 5 & 6 & 4 \\
\hline \multicolumn{2}{|c|}{ Total } & 0 & 9 & 13 & 20 & 19 & 19 & 6 & 2 & & 21 & 29 & 20 & 40 & 33 & 36 & 24 \\
\hline \multicolumn{2}{|c|}{ Mean } & 0 & 1. 1 & 1.6 & 2.5 & 2.3 & 2.3 & 0.7 & 0.2 & & 2.6 & 3.6 & 2.5 & 5.0 & 4.1 & 4.5 & 3.0 \\
\hline
\end{tabular}

before and after the booster dose were essentially the same in the three groups, except that the control group and the lightly infestated group reached the peak agglutinin response one week earlier than the heavily infestated group. It can also be seen that the responses of the infestated animals of groups A and B fell abruptly to a very low mean titer in the 7 th week, whilst that of the control group sustained longer at a conspicuous level. There was a very significant 
Table 3. Agglutinin-titer scores of uninfestated guinea pigs (Group C)

\begin{tabular}{|c|c|c|c|c|c|c|c|c|c|c|c|c|c|c|c|c|c|}
\hline \multirow{2}{*}{$\begin{array}{l}\text { G. P. } \\
\text { No. }\end{array}$} & \multirow{2}{*}{$\begin{array}{l}\text { Ova } \\
\text { count }\end{array}$} & \multicolumn{16}{|c|}{ Week after first injection of antigen } \\
\hline & & 1 & 2 & 3 & 4 & 5 & 6 & 7 & 8 & & 17 & 18 & 19 & 20 & 21 & 22 & 23 \\
\hline $\mathrm{C} 1$ & Nil & 0 & 4 & 5 & 5 & 4 & 3 & 1 & 4 & \multirow{8}{*}{ 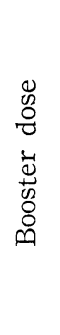 } & 5 & 5 & 2 & 7 & 8 & 6 & 5 \\
\hline $\mathrm{C} 2$ & " & 3 & 3 & 6 & 5 & 6 & 5 & 1 & 3 & & 6 & 6 & 5 & 7 & 6 & 4 & 4 \\
\hline C 3 & "I & 0 & 1 & 4 & 3 & 2 & 2 & 4 & 1 & & 3 & 5 & 1 & 6 & 7 & 7 & 6 \\
\hline $\mathrm{C} 4$ & " & 0 & 1 & 1 & 4 & 4 & 3 & 3 & 1 & & 3 & 4 & 3 & 9 & 6 & 4 & 4 \\
\hline C5 & " & 0 & 2 & 2 & 2 & 4 & 3 & 4 & 1 & & 3 & 5 & 2 & 6 & 6 & 5 & 5 \\
\hline $\mathrm{C} 6$ & " & 0 & 3 & 6 & 6 & 5 & 4 & 1 & 4 & & 3 & 4 & 0 & 5 & 5 & 4 & 4 \\
\hline $\mathrm{C} 7$ & "I & 0 & 2 & 5 & 4 & 3 & 3 & 1 & 2 & & 4 & 4 & 2 & 7 & 7 & 6 & 6 \\
\hline $\mathrm{C} 8$ & " & 0 & 3 & 7 & 5 & 5 & 6 & 4 & 21 & & 2 & 5 & 2 & 6 & 6 & 5 & 4 \\
\hline \multicolumn{2}{|c|}{ Total } & 3 & 19 & 36 & 34 & 33 & 29 & 19 & 18 & & 29 & 38 & 17 & 53 & 51 & 41 & 38 \\
\hline \multicolumn{2}{|c|}{ Mean } & 0.3 & 2. & 4.5 & 4. & 4.1 & 3.6 & 2. & 2.2 & & & 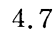 & & 0. & & 35.1 & 4.7 \\
\hline
\end{tabular}

Table 4. Values of $t$ on the differences between means of experimental and control groups

\begin{tabular}{clll}
\hline & \multicolumn{3}{c}{ Probability value (p) between groups } \\
\cline { 2 - 4 } Week & A \& C & B \& C & A \& B \\
\hline 2nd & 0.4478 & 0.9065 & 1.1227 \\
3rd & 1.7084 & $3.5068^{* *}$ & $3.0740^{* *}$ \\
4th & 1.7042 & $2.7195^{*}$ & 1.2675 \\
5th & 1.8230 & $2.1751^{*}$ & 1.1744 \\
6th & $3.1691^{* *}$ & 1.7400 & 0.5390 \\
7th & $3.2246^{* *}$ & $2.4326^{*}$ & 0.1747 \\
8th & $4.7372^{* * *}$ & $4.1876^{* * *}$ & 0.3631 \\
\hline 17th & 1.9141 & 0.9938 & 0.5367 \\
18th & 0.7172 & 2.0360 & 1.7824 \\
19th & $2.6972^{*}$ & 0.5818 & $3.9431^{* * *}$ \\
20th & 1.7733 & 3.0970 & 0.4673 \\
21st & $3.4208^{* *}$ & $4.2446^{* * *}$ & 1.1574 \\
22nd & 2.0419 & 0.9574 & 0.7971 \\
23rd & 2.5150 & $4.2569^{* * *}$ & 1.2999 \\
\hline
\end{tabular}

* $\quad \mathrm{p}<0.05$, significant.

** $\mathrm{p}<0.01$, highly significant.

*** $\mathrm{p}<0.001$, very highly significant.

negative phase in all three groups in the 19 th week, i. e. 3 weeks after the booster dose. The fall was most marked in group A, least in group B and with the control group in between.

Statistically, the difference between the mean titers of group B and the control was highly significant from the 3 rd week until the 8 th week when analysis was 


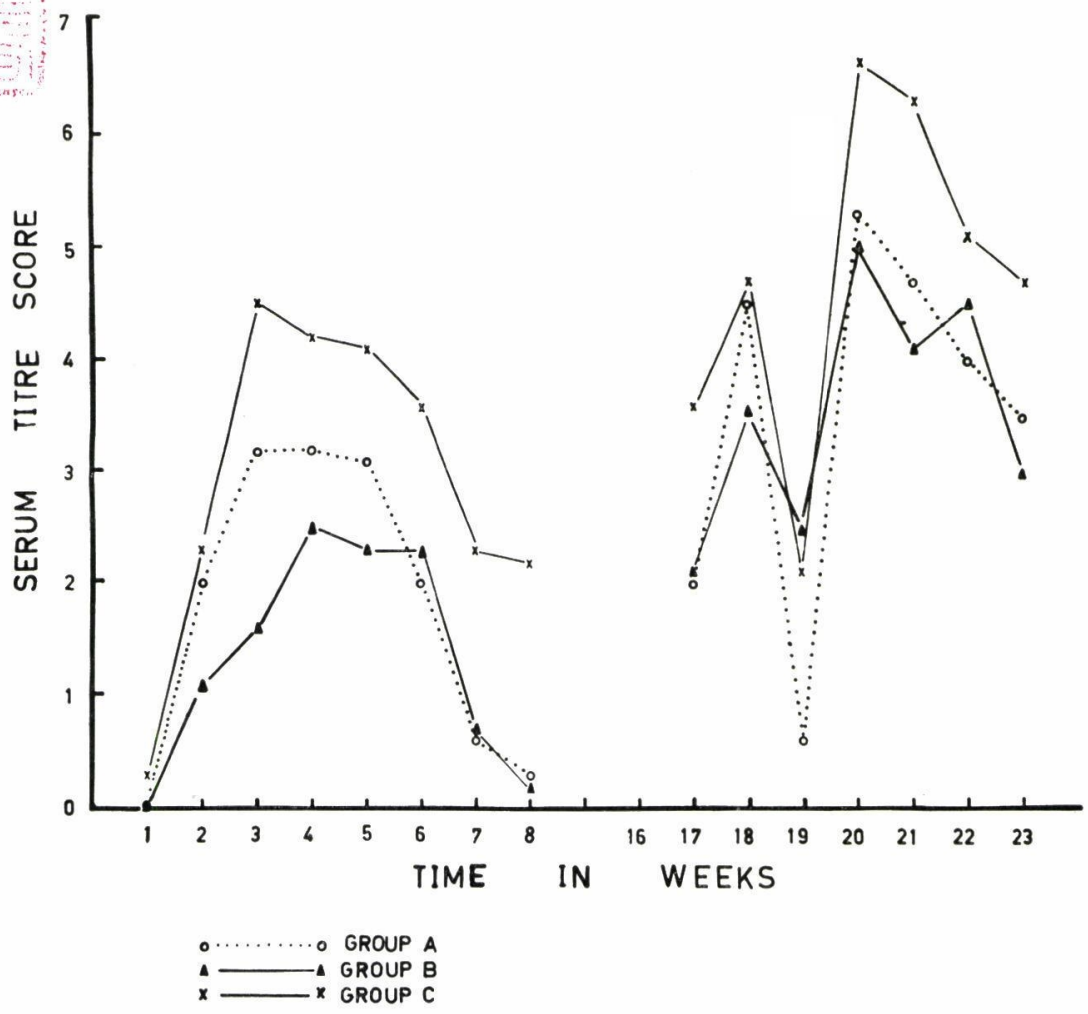

Fig. 2. Rise and fall of mean agglutinin-titers of the three groups of guinea pigs. Group A are those with light infestation, B with heavy infestation and $\mathrm{C}$ the uninfestated control.

temporarily terminated (Table 4). The difference between the mean titers of group $\mathrm{A}$ and the control group was also significant but it was delayed to the 6th week. There was, however, no significant difference between the mean titers of the two infestated groups except in the 3rd week when the mean titer of the lightly infestated group was at its peaks, whereas that of the heavily infestated group was still rising. The mean agglutinin titers after a single booster dose of antigen injected on the 16th week between the infestated and the control groups showed a significant difference from the 20th week onwards. Again, a more marked difference is seen between the heavily infestated group and the control.

On the whole, there was statistically significant reduction in agglutinins produced by clonorchis infestated guinea pigs as compared with the uninfestated controls. The reduction was especially marked in animals with heavier infestation,

\section{DISCUSSION}

The role of the liver in production of antibodies is still poorly defined. Burnet and Fenner (1949) suggested that the reticulo-endothelial components of the liver may participate in antibody production. Sabin (1939) in a study of the fate of 
particulate antigens revealed their presence in the von Kuffer cells. Crampton and Haurowitz (1951) and Ranney and London (1951) supported the concept that the liver participates in the formation of antibodies. Humphrey and White however, maintained that antibody production within the liver could usually correlate with the presence of invading cells forming scattered periportal granulomata and the true hepatic parenchymal cells do not make antibodies.

Khaw (1929) observed extensive tissue-reaction with a special form of cirrhosis induced in the liver of clonorchis infestated guinea pigs. Hou (1955), however, described multiple scar formation with disappearance of the liver cells but no true cirrhosis. Through our observation accorded with Hou, it must be noted that the degree of parasitization or the worm load bears direct relationships to the tissue changes. In an experiment in which guinea pigs infestated with 40-50 worms, the liver was mainly composed of dilated bile ducts lined with a single layer of epithelial cells and with very little liver parenchymal cells left due to compression (unpublished data).

The highly significant reduction in the typhoid H-agglutinin production during a prolonged course of clonorchis infestation was observed in the guinea pigs and this was more so in those animals which bear a bigger worm load. The reduction of typhoid $\mathrm{H}$-agglutinin titers must be directly related to the compression of the liver cells adjacent to the bile ducts. There were no gross changes in the spleen and the low antibody titers in the infestated animals was not due to the influence of the "hypersplenic" effect on plasma cells as suggested by McFadzean and Tsang (1956). As there is no true cirrhosis, the low response cannot be attributed to accelerated degradation of gamma-globulin as Eisenmenger and Slater (1953) described in patients with cirrhosis of liver.

Uehara (1963) and Sun (1967) reported increase of serum globulin especially gamma-globulin in rabbits and guinea pigs experimentally infestated with Clonorchis sinensis. Since the infestation with the worms and the injection of the typhoid antigen were not simultaneous, there is no suppression of antibody production tissues due to "swamping" by one antigen upon another. The findings in this study, however, have little practical importance in human clonorchiasis in which the extent of damage to the liver cells in mild (Hou, 1955), yet it reveals the fact that compression of the liver parenchyma due to considerable dilatation of the bile ducts can lead to reduction of overall antibody response for an antigen.

\section{ACKNOWLEDGEMENT}

The authors wish to thank Dr. T. B. Teoh for his help in the description of the histological changes, Dr. S. T. Chan for her assistance in statistical analysis of the data and Dr. T. Sun for supplying figure 2 .

\section{REFERENCES}

Burnet, F. M. AND Fenner, F. (1949): Production of Antibodies. 2nd edition, MacMillain, Melbourne.

CRAmPton, C. F. AND HAUROWITZ, F. (1951): Intracellular distribution of radioiodinated antigens. Federation Proc., 10, 405.

Eichman, P. L., Miller, R. W. And Haven, W. P. (1953): The production of antibody by 
patients with acute viral hepatitis. J. Immunol., 70, 21-30.

EISENMENGER, WM. J. AND SlATER, R. J. (1951): Distribution and decay of $\mathrm{I}^{131}$ tagged albumin and gamma globulin in patients with cirrhosis. J. Clin. Investig., 32, 564-573.

FAust, E. C. AND KHAW, O. K. (1927): Studies on Clonorchis sinensis (Cobbold). Am. J. Hyg. Monogr. Ser. 8.

FaUst, E. C. AND RUSSEL, P. F. (1964): Clinical Parasitology. 7th edition, Lea and Febiger, Philadelphia.

Hou, P. C. (1955): The pathology of Clonorchis sinensis infestation of the liver. J. Pathol. Bacteriol., 70, 53-64.

HUMPHREY, J. H. AND WHITE, R. G. (1963): Immunology for Students of Medicine. 1st edition, Blackwell Sci. Pub., Oxford.

KHAW, O. K. (1929): Experimental infection of guinea pigs with clonorchis cysts in fishes. Peking Soc. Natural Hist. Bull., 4 (Pt. IV), 19-24.

McFAdZEAN, A. J. S. AND TSANG, K. C. (1956): Antibody formation in cryptogenic splenomegaly. Tran. Roy. Soc. Trop. Med. Hyg., 50, 433-441.

UEHARA, K. (1963): Studies on serum protein in clonorchiasis sinensis. Tokushima J. Exptl. Med., 9, 186-227.

RANNEY, H. M. AND LONDON, I. M. (1951): Antibody formation in surviving tissues. Federation Proc., 10, 562-563.

SABIN, F. R. (1939): Cellular reactions to a dye-protein with a concept of the mechanism of antibody formation. J. Expt1. Med., 70, 67-81.

Sun, T. (1967): Immunological studies in clonorchiasis. M. Sc. Thesis, University of Hong Kong. 